$\mathbf{X X}$.

Kleinere Nlittheilungen.

1.

\title{
Peritonaeale Metastasen eines Eierstocksdermoids und eines Beckensarcoms.
}

\author{
Von Dr. Kolaczek, \\ Privatdocent und Secundärarzt der königl. chirturg. Klinik in Breslau.
}

Unter den echten Geschwïlsten ist es bekanntlich vor Allem der Krebs, der unter dem Bilde einer Peritonitis zahlreiche knotige Metastasen am Bauchfell macht. Eine sarcomatöse Peritonitis dürfte schon zu den Seltenheiten gebören, weshalb ich diese Gelegenheit benütze, um an zweiter Stelle über eine solche zu berichten.

Zunächst aber erlanbe ich mir durch ein kurzes Referat das bisher vielleicht noch nie beobachtete Vorkommniss einer Peritonitis durch multiple miliare Metastasen eines Eierstocksdermoids zu constatiren und so der Vergessenheit zu entreissen.

Bei einer am 9. Sep. 1877 von Herrn Dr. Martin i in Breslau unter meiner Assistenz ausgeführten 0variotomie fielen mir nach Abfluss des bedeutenden serösen Exsudats an dem Parietal-, sowie vornehmlich am Visceralblatte des Bauchfells zahlreiche, bis nahezu linsengrosse, leicht gelbliche Knötchen in die Augen, die gleich den miliaren Tuberkeln auf einem intensiv injicirten Grunde sassen. Da bls zur Operation nicht das geringste Verdachtsmoment für eine Tuberculose des Bauchfells sprach, so prüfte ich den überraschenden Befund, soweit es die Umstände erlaubten, etwas näber und entdeckte in vielen dieser Knötchen inmitten ein feines, bis $1 \mathrm{~cm}$. langes, lichtes Wollhaar, das frei in die Bauchböhle hineinragte. Ich extrahirte einige dieser Härchen, und konnte sie als solche mikroskopisch vollständig bestätigen. Die fast mannskopfgrosse dickwandige Cyste selbst, hatte eine platte, von den erwähnten Knötchen ganz freie Oberfäche, in der Mitte aber enthielt sie in einem über faustgrossen Hoblraume ein ebenso grosses Convolut in dichter Talgwasse eingebetteter aschfarbiger langer Haare. Im Uebrigen unterschied sich der Tumor von den gewöhnlichen Dermoidcysten nicht wesentlich. - Die Patientin war eine 45jährige Jungfrau, die erst in den letzten sieben Jahren eine zunehmende Schwellung ihres Unterleibes wahrgenommen hatte.

Am 5. Juli d. J. bemerkte ich bei Gelegenheit einer von demselben Herrn Collegen wegen eines Beckentumors ausgeführten Laparotomie bei einer Frau von 33 Jahren auf dem Bauchfelle eine Anzahl bleiner, bis erbsengrosser Geschwülste von papillarer Form und oft himbeerartigem Aussehen der Oberfläche. Da der Beckentumor ringsum dicht und fest verlöthet war, so liess sich nach Spaltung seiner peritowaealen Decken nur ein Theil davon entfernen, wobei er sich als aus mul- 
tiplen kleinen Cysten bestehend erwies. Die Schnittänder des serösen Geschwulstüberauges warden mit den Wundrändern der Bauchwand innig vereingt und so ein leichter Abfluss der Höhlensecrete geschaffen. Trotzdem trat nach fünf Tagen der Tod ein. Herr College Martini hatte die Güte, von der nur sehr beschränkt zugelassenen Autopsie einen Theil der Geschwulstwand im Zusammenhange mit einem Stück der Harublase mir zuzustellen. In das Lumen derselben ragten nehmlich von der hintern Wand zwei, an dünnen Stielen sitzende, polypös-papillare Tumoren hervor, der eine fast wallnuss-, der andere kleinhaselnussgross. Der Harnblasenwand selbst, die übrigens von der Gesehwulstwand vicht zu differenziren war, fanden sich ähnliche kleine Geschwülste eingelagert, anscheinend frei in Hoblräımen, bei genauerem Zusehen aber auch feingestielt. Der Ausgangspunkt der Neubildung im Becken konnte nicht genau festgestellt werden. - Die beiden Harnblasentumoren, deren Stiele ungefähr stricknadeldick waren, stellten exquisite Fälle eines Papilloma arborescens telangiectaticum vor. Mikroskopisch entsprachen sie etwa einem Spindelzellensarcom; nur in den ăussersten Ansläufern der Neubildung waren die oft mebrfachen Scblingen der weiten Capillaren von Rundzeilen eingehüllt. Einen merkwürdigen Befond bildeten an vielen Stellen besonders nahe der Oberläche eingelagerto Kalkconcremente, oft mit deutlicher Anordnung um Blutgefâsse herum. Nicht selten zeigten die grösseren Concremente eine concentrische Scbichtnng und glichen vollständig den Sandkörnern der Psammome. Dieselben Kalkaiederschläge fanden sich in Form eines parallel der Innenfläche der Geschwulsteysten verlanfenden und unmittelbar unter ihr gelegenen schmalen Bandes. Stellenweise zeigte die Innenwand der Cysten die Neigung papillär auszuwuchern. Solche Proliferationsstellen verriethen sich im Beginne des Prozesses durch sehr dicht gruppirte, weite Gefässe von sonst capillarem Charakter und geringer perivasculärer Zellenwucherung. Die in der verschmolzenen Cysten- und Harnblasenwand in den Spaiten gelegenen Tumoren hahen sich allem Anscheine nach innerbalb ursprünglicher Gefässlumina, also intracanaliculär, entwickelt. Dafür sprach wenigstens das Vorkommen eystisch erweiterter venöser Gefässlumina innerhalb der Wand, in welche das perivasculäre Bindegewebe papillär hineinzuwuchern anfing. Die intramuralen Geschwülste, wenn sie so genannt werden dürfen, glichen in jeder Beziehung ganz und gar den schon heschriebenen Blasenhöhlentumoren, so dass mit aller Wabrscheinlichkeit anzunehmen ist, dass auch die papillären Wucherungen auf dem Baucbfelle yon derselben Beschaffenheit sein werdea.

Obgleich die Ueberschrift dieses kleinen Aufsatzes beiden Geschwülsten einen metastatischen Cbarakter zugesichert hat, so erscbeint es mir wenigstens schwer, über den metastatischen Vorgang bei denselben mir eine bestimmte Vorstellung za machen. Denn die für multiple Peritonaealgescbwülste sonst begründete Annahme eines Seminium lässt uns bei dem Dermoid ganz im Stich, weil der primäre Tumor mit einer ganz glatten, unschuldigen, jeden Samens entbebrenden Oberfläche in die Bauchhöhle hineinblickte. Ebensowenig wabrscheinlicb dürfte ein Transport von Dermoidkeimen durch Gefässe und Ablagerung derselben grade an der Oberfläche des Bauchfells sein. Sollte nicht vielmehr dieses gleichzeitig mit dem Eierstock im embryonalen Leben von einem Febler primae formationis betroffen und mit den Keimen wirklicher Deckepithelien durchsetzt worden sein? 
Auch für die zweite Geschwulst erscheinen mir die üblicben, anf eine Metastase binzielenden Erklärungsgründe nicht so zutreffend, wie die Vorstellung, dass das Bindegewebe eines ganzen Territoriums unter dem unbekannten, geschwulsterzeugenden Einflusse die Neigung gewann, die dasselbe bedecbenden,endothelialen Flächen gewisser Hohlräume papillär in das Lumen vorzudrängen. Findet sich doch auch die Körperoberfäche nicbt so selten mit multjplen, meist gutartigen Tumoren besetzt, ohne dass man ein Recht bätte, in einem solchen Falle von Metastasen zu reden.

2.

\title{
Sensibilität der Schädelnähte.
}

\author{
Von Dr. M. Fraenkel, \\ Director der Landes-Irrenanstalt bei Bernburg.
}

Gelegentlich der Untersuchungen und Messungen an den Köpfen geistesgestörter Individuen, welche in die Irrenanstalt aufgenommen wurden, desgleichen bei Geistesgesunden stiess ich schon vor Jahren auf eine Thatsache, welche wenig oder gar nicht bekannt, um der aus ihr herzuleitenden Folgerungen willen wobl beachtenswerth erscheint. Ich fand nebmlich, dass die Kopfhaut über den Nähten empfindlicher sich verhielt als die an den Flächen und Vorsprüngen der'Schädelknochen, oder vielmebr, wie sich später herausstellte, dass die Nahtrerbindung eine höhere Sensibilität besitzt, als die übrigen Knochentheile.

Es ist das namentlich an der Stelle der Fall und leicht zu ermitteln, wo die Kranznaht mit der Pfeilnaht zusammenstösst. Um sich von der Richtigkeit der Sache zu überzeugen bedarf es nur des Einsetzens eines Fingernagels, mit dem man über die unbehaarte Stirnhaut binweg aufwărts gegen die meist vertiefte Gegend der ehemaligen grossen Fontanelle (das Bregma) streicht.

Empfindet man dabei unterbalb fast nur die Berührung, so meint man einen Schnitt wahrzunehmen, sobald die genannte Stelle getroffen wird. Setzt man statt des Nagels die Fingerspitze mit auch nur gering verstärktem Drucke ein, so zeigt sich eine Art dumpfen betäubenden Scbmerzgefühls, das nach allen Richtungen der nächsten Umgebung ausstrahlt. Beide Experimente gelingen, und zwar an allen erreichbaren Nähten des Schädels, am besten bei jungen und bei sensibleren Individuen, seltener oder gar nicht bei Greisen, wahrscheinlich in Folge des theilweisen oder gänzlichen Verstreichens der Nähte. Am Empfindlichsten scheinen die Nähte in der Gegend der ehemaligen Fontanellen zu sein, nicht allein der grossen, sondern auch der kleinen und Seitenfontanellen. Bei Individuen, die an Hyperăsthesie Jeiden, ist der Druck auf diese Stellen so sebmerzhaft, dass man den Zustand als Raphalgfa cranii bezeichnen könnte. Untersucht man Säufer, die bekanntlich häufig an Hyper- und Parästhesien der Haut leiden, in dieser Richtung, so erkennt man den Grad der Hyperästhesie mittelst eines Fingerdruckes auf den Kopf leichter als durch eine andere Methode. So befindet sich gegenwärtig bei mir ein 40 jähriger Schmiedegesell in Behandlung, ein exquisiter Potator von colossalem Knochengerüst 